DOI: https://doi.org/10.31933/jemsi.v2i3

Received: 26 November 2020, Revised: 15 Desember 2020, Publish: 31 Januari 2021

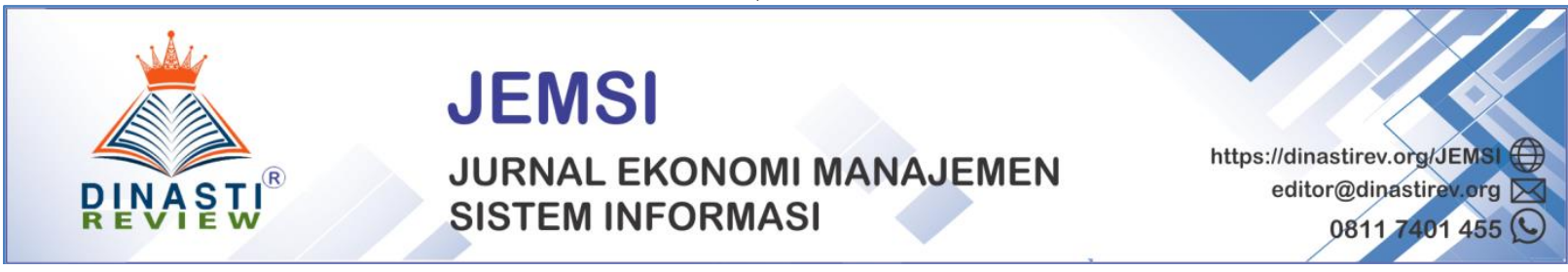

\title{
PENYALURAN KREDIT USAHA KECIL MELALUI PT. BANK RAKYAT INDONESIADAPAT MENINGKATKAN PEREKONOMIAN PENGUSAHA KECIL
}

\author{
Albert Andreas Mangatur Tambunan \\ Universitas Terbuka, alberttambunan5@gmail.com
}

\section{Corresponding Author: Albert Andreas Mangatur Tambunan}

Abstrak: Amanat Undang-undang Dasar 1945 menyatakan seluruh kekayaan Negara dikelola untuk kemakmuran rakyat. Pajak yang diperoleh dari rakyat, hasil tambang dan laut, dan juga penghasilan lainnya (utang luar negeri), dimana seluruh dana ini tercermin di dalam APBN (Anggaran Pendapatan dan Belanja Negara), dikelola demi pengejawantahan amanat untuk kemakmuran rakyat tersebut. Dengan jumlah yang sangat besar tersebar di seluruh Indonesia, Usaha Kecil dan menengah cukup banyak menyerap tenaga kerja, namun mempunyai hambatan-hambatan untuk dapat berkembang dengan cepat. Mereka sebagai sasaran utama penyaluran kredit. Pihak perbankan kurang melirik pengusaha kecil karena terkendala dengan prinsip perbankan yang harus hati-hati (prudent). Pengusaha besar cenderung sudah mempunyai laporan keuangan sesuai ketentuan-ketentuan akuntansi moderen, dan juga sudah diaudit oleh akuntan publik. Tentang agunan kredit juga bermasalah, karena pengusaha kecil memiliki asset berupa tanah yang rata-rata tidak memiliki sertipikat, tetapi hanya surat keterangan tanah dari kepala desa atau camat, atau hanya sebagai penggarap tanpa adanya keterangan kepemilikan tanah. Namun setelah krisis moneter tersebut, dan setelah reformasi, pemerintah mempunyai paradigma baru, bahwa pengusaha kecil dan menengah adalah juga pilar perekonomian Indonesia.Untuk menghilangkan hambatan permodalan ini, pemerintah meluncurkanprogram Kredit Usaha Kecil dengan persyaratan administrasi yang ringan.Program penyaluran KUR ini dimulai sejak tahun 2007 sampai sekarang, disalurkan pertama kali oleh Bank Usaha Milik Negara.

Keywords : ekonomi, kredit-mikro, bank

\section{PENDAHULUAN}

\section{Latar Belakang}

Kesenjangan kekayaan antara konglomerat dan pengusaha kecil di Indonesia sangat tinggi. Pemerintahan Orde Baru berorientasi meningkatkan pertumbuhan ekonomi dan mencanangkan menciptakan sebagian kecil konglomerat dengan asumsi akan terjadi 
trickledowneffect, dimana pengusaha konglomerat akan mengangkat pengusaha kecil sebagai mitranya atau anak asuhnya. Model ini dipakai dengan harapan agar dapat terjadi percepatan pertumbuhan ekonomi sekaligus pemerataan pendapatan.Namun trickle down effect tersebut tidak terjadi. Para pengusaha kecil tetap berada dalam lingkaran kemiskinan, terutama di pedesaan. Tingkat pertumbuhan ekonomi relative tinggi tapi tingkat kemiskinan juga meningkat.

Untuk mengukur tingkat pemerataan pendapatan nasional dipakai koefisien Gini (Index Gini). Koefisien Gini (Todaro: 1995) merupakan keseluruhan ukuran ketidak merataan dan dapat bervariasi dari nol (kesamarataan sempurna) sampai dengan satu (ketidakmerataan sempurna). Koefisisen Gini untuk Negara-negara dengan distribusi pendapaatan yang relative tidak sama (tidak merata) koefisien Gininya terletak antara 0,5 dan 0,7, sementara untuk Negara-negara dengan distribusi pendapatan yang relative sama (merata) koefisien Gininya terletak pada urutan 0,2 sampai dengan 0,35 .

Setelah reformasi, pemerintah merobah paradigma pembangunan ekonomi dengan langsung fokus membantu pengusaha kecil dengan memberikan modal sehingga dikeluarkanlah kebijaksanaan mengucurkan fasilitas Kredit Usaha Kecil (KUR) dengan persyaratan yang sederhana dan relatif ringan. Secara teori, dengan program KUR ini perekonomian rakyat akan berkembang, dengan demikian tingkat pertumbuhan perekonomia negara juga akan meningkat (Produk Domestik Bruto/PDB meningkat).

Laporan Bank Dunia yang dikeluarkan pada Desember 2015 menyatakan hanya $20 \%$ (dua puluh persen) dari penduduk Indonesia yang menikmati buah pertumbuhan ekonomi selama dekade lalu (tahun 1990 -2000), dan $80 \%$ (delapan puluh persen) dari 200 juta penduduk tertinggal di belakang. Pertumbuhan ekonomi pada dekade tersebut cukup tinggi $(6 \%)$.

Krisis keuangan yang dilanjukan dengan krisis ekonomi pada tahun 1998, mengakibatkan pengusaha besar (konglomerat) mengalami kebangkrutan, sedangkan pengusah kcil dan menengah dapat bertahan,karena lebih lebih banyak memakai modal sendiri daripada mengandalkan pinjaman dari bank. 
Kemampuan beratahan (survive) dari pengusaha kecil dan menengah ini menarik perhatian pemerintah, dan memikirkan program apa yang dapat dibuat agar dapat membantu kesulitan-kesulitan yang dialami oleh pengusah kecil dan menengah. Salah satu kesulitan yang dihadapi pengusaha kecil dan menengah adalah menyangkut permodalan yang terbatas.

Program Kredit Usaha Kecil dimulai pada tahun 2007.Pemerintah menyalurkan KUR pertama kali melalui Bank Usaha Milik Negara.Salah satunya adalah BRI. Setiap tahun pemerintah mengevaluasi bank-bank penyalur KUR, dan alokasi dana yang disalurkan ditambah kepada bank yang memiliki prestasi pencapaian target tertinggi. BRI mendapat kepercayaan dari pemerintah dengan menambah dana KUR untuk disalurkan setiap tahunnya.

Dengan penyaluran KUR pada pengusaha kecil ini dapat meningkatan pendapatan para pengusaha.Penelitian dilakukan di BRI, Cabang Pembantu Kecamatan Tanjung Pura, Kabupaten Langkat.

Animo pengusaha kecil untuk memperoleh KUR cukup tinggi, terutama di tingkat kecamatan, dengan permintaan pinjaman berkisar antara Rp.50.000.000,- sampai Rp. 500.000.000,- dari setiap pinjaman KUR yang diterima dapat dihitung persentase peningkatan pendapatan per bulan s/d per tahunnya atau dengan kata lain ada korelasi antara perolehan fasilitas KUR dengan peningkatan penghasilan dari usaha.

\section{Tujuan Penelitian}

1. Untuk lebih mengetahui lebih dalam tentang KUR dan pengaruhnya terhadap peningkatan penghasilan pengusaha, terutama pengusaha kecil dari berbagai jenis usaha

2. Untuk dapat dipakai sebagai bahan penelitian berikutnya atas masalah yang ditelit

\section{PerumusanMasalah}

1. Apakah fasilitas KURberpengaruh terhadap penghasilan pengusaha kecil

2. Bagaimana korelasi jumlah pemberian KUR terhadap tingkat laba

\section{Tinjauan Pustaka}

Pasal 33 ayat (3) Undang-undang Dasar 1945 (amandemen) berbunyi :"Bumi dan air dan kekayaan alam yang terkandung di dalamnya dikuasai oleh negara dan dipergunakan sebesarbesarnya untuk kemakmuran rakyat", danayat(4)berbunyi : "Perekonomian nasional 
diselenggarakan berdasar atas demokrasi ekonomi dengan prinsip kebersamaan , efisiensi, berkeadilan, berkelanjutan, berwasan lingkungan, kemandirian, serta dengan menjaga keseimbangan kemajuuan dan kesatuan ekonomi nasional”.

Dari bunyi undang-undang dasar tersebut di atas, mengamanatkan bahwa pemerintah sebagai pengelola Negara akan mengupayakan pengelolaan kekayaan Negara untuk memakmurkan seluruh rakyat Indonesia. Dalam pengelolaan tersebut tetap dipelihara kesinambungan untuk generasi penerus.

Salah satu upaya pemerintah memperhatikan rakyat (pengusaha kecil) adalah dengan mengeluarkan kebijakan penyaluran kredit untuk pengusaha kecil yang disebut Kredit Usaha Kecil (KUR).Pengusaha kecil mempunyai keterbatasan terutama dalam pemilikan modal dan akses ke perbankan untuk memperoleh pinjaman, karena bank pada dasarnya menerapkan kriteria-kriteria yang ketat dalam menyalurkan kredit.

Undang-undang Nomor 20 Tahun 2008 tentang Usaha Mikro, Kecil dan Menengah (UMKM) memberikan beberapa definisi/ketentuan umum atas beberapa hal sebagai berikut : Usaha Mikro adalah usaha produktif milik orang perorangan dan/atau badan usaha perorangan yang memenuhi kriteri Usaha Mikro sebagaimana diatur dalam undang-undang (hasil penjualan paling banyak Rp.100.000.000,- per tahun), sedangkan Usaha Kecil adalah usaha ekonomi produktif yang berdiri sendiri, yang dilakukan oleh orang perorangan atau badan usaha yang bukan merupakan anak perusahaan atau bukan cabang perusahaan yang dimiliki, dikuasai, atau menjadi bagian baik langsung maupun tidak langsung dari usaha menengah atau usaha besar yang memenuhi kriteria Usaha Kecil sesuai undang-undang (Kekayaan bersih paling banyak Rp.200.000.000,- dan penjualan per tahun paling banyak Rp. 1.000.000.000,-). Terakhir, Usaha Menengah adalah usaha ekonomi produktif yang berdiri sendiri, yang dilakukan oleh orang per orangan atau badan usaha yagn bukan merupakan anak perusahaan atau cabang perusahaan yang dimiliki, dikuasai atau menjadi bagian baik langsung maupun tidak langsung dengan usaha kecil atau usaha besar dengan jumlah kekayaan bersih lebih besar dari Rp.200.000.000,- (dua ratus juta)sampai dengan paling banyak Rp.10.000.000.000,(sepuluh milyar rupiah).

Pada tanggall8 Juni 2007, Presiden mengeluarkan Instruksi Presiden(INPRES) No. 6 Tahun 2007 tentang Kebijakan Percepatan Pengembangan Sektor Riil dan Pemberdayaan Usaha 
Mikro, Kecil, dan Menengah. INPRES ini dikeluarkan dalam upaya untuk lebih mempercepat pengembangan sektor riil dan pemberdayaan usaha mikro, kecil dan menengah guna meningkatkan pertumbuhan ekonomi nasional dan sebagai kelanjutan Instruksi Presiden Nomor 3 tahun 2006 tentang Paket Kebijakan Perbaikan Iklim Investasi.

KUR tahap pertama(Latif Adam : 2018) mulai November 2007 - Desember 2014, merupakan bagian dari program percepatan penanggulangan kemiskinan. Sedangkan KUR tahap kedua dimulai pada Agustus 2015 sampai sekarang, lebih diarahkan sebagai stimulus untuk mendorong pertumbuhan ekonomi yang sedang mengalami perlambatan.

Lebih lanjut tentang KUR ini diatur dalam Peraturan Menteri Keuangan Republik Indonesia Nomor 22/PMK.05/2010 sebagai berikut; Pasal 5 ayat (1): UMKMKyangdapatmenerimafasilitaspenjaminanaKURadalahusahaproduktifyangfeasible namun belum bankable,yang merupakan calon debitur yang tidak sedang menerima kredit modal kerja dan/atau investasi dari perbankan dan/atau yagn tidak sedang menerima Kredit Program dari Pemerintah yang dibuktikan dengan hasil Sistem Informasi Debitur pada saat Permohonan KUR diajukan. Kemudian ayat (2) menegaskan :KUR yang disalurkankepada UMKM-K dapat digunakan bank untuk kredit modal kerja maupun kredit investasi, dengan ketentuan, a).paling tinggi sebesar Rp.5.000.000,00 (lima juta rupiah) dengan tingkat bunga kredit/margin pembiayaan paling tinggi sebesar/setara $22 \%$ (dua puluh dua persen) efektif per tahun atau ditetapkan lain oleh Menteri Keuangan atas rekomendasi Komite Kebijakan; b). di atas Rp. 5.000.000,00 (lima juta rupiah) sampai dengan Rp.500.000.000,00 (lima ratus juta rupiah) dengan tingkat bunga kredit/margin pembiayaan yang dikenakan paling tinggi sebesar/setara $14 \%$ (empat belas persen) efektif per tahun atau ditetapkan oleh Menteri Keuangan atas rekomendasi Komite Kebijakan.

\section{METODE PENELITIAN}

\section{Subyek Penelitian :}

Subyek penelitian adalah PT. Bank Rakyat Indonesia (BRI), Ltd., yang menyalurkan Kredit Usaha Kecil kepada nasabahnya. Lebih lanjut fokusnya adalah BRI Kantor Cabang Pembantu Tanjung Pura, Kabupaten Langkat

Populasi dan sampel: 
Polulasi yang dipakai adalah para nasabah yang memperoleh fasilitas Kredit Usaha Kecil. Teknik pemilihan sampel dengan cara Purposive Sample, yaitu18 nasabah yang memperolehKUR.

\section{Teknik pengumpulan data:}

Mengumpulkan data-data sekunder penerima KUR, membuat table data nasabah terkait dengan, umur, tingkat pendidikan, jumlah modal, lama berwiraswasta, jenis usaha, penghasilan ketika menggunakan modal sendiri.Hal ini diperoleh dengan mengumpulkan dokumen serta observasi.Membuat tabulasi awal periode penerimaan KUR, melakukan wawancara untuk memperoleh data penghasilan sebelum dan sesudah menerima KUR, membuat angket.

Metode analisa yang digunakan dalam tulisan ini adalah deskriptif kualitatif yaitu menerangkan dan menafsirkan data-data yang dikumpulkan untuk menjelaskan secara sistematis pengaruh pemberian fasilitas KUR terhadap peningkatan penghasilan pengusaha kecil.

\section{HASIL PENELITIAN DAN PEMBAHASAN}

Tabel 1. Data-data Nasabah yang Memperoleh KUR di BRI Tanjung Pura

\begin{tabular}{|c|c|c|c|c|c|c|c|c|c|c|}
\hline No & Nama & $\begin{array}{l}\text { Plafon } \\
\text { Rp. } \\
(000)\end{array}$ & $\begin{array}{c}\text { Realisasi } \\
\text { (tgl) }\end{array}$ & $\begin{array}{l}\text { Umur } \\
\text { (thn) }\end{array}$ & $\begin{array}{l}\text { Pendi- } \\
\text { dikan }\end{array}$ & Jenis Usaha & $\begin{array}{l}\text { Lama } \\
\text { usaha } \\
\text { thn) }\end{array}$ & $\begin{array}{l}\text { Laba } \\
\text { dengan } \\
\text { modal } \\
\text { sendiri } \\
\text { (Rp.000) }\end{array}$ & $\begin{array}{l}\text { Laba } \\
\text { Setlh } \\
\text { KUR } \\
(\text { RP ) } \\
(000)\end{array}$ & $\begin{array}{l}\text { Laba } \\
\text { Naik } \\
(\%)\end{array}$ \\
\hline 1 & A1 & 100.000 & $18 / 08 / 2019$ & 54 & SMA & Sawit,kedai & 6 & 75.168 & 78.175 & 4 \\
\hline 2 & $\mathrm{~A} 2$ & 200.000 & $04 / 10 / 2019$ & 45 & SMA & Tambak udang & 4 & 60.230 & 62.940 & 4,5 \\
\hline 3 & $\mathrm{~A} 3$ & 200.000 & $28 / 10 / 2019$ & 57 & SMA & Jual-beli botot & 12 & 180.812 & 195.272 & 8 \\
\hline 4 & A4 & 500.000 & $30 / 10 / 2019$ & 60 & SMA & $\begin{array}{l}\text { Ternak lembu, } \\
\text { sawit, karet }\end{array}$ & 15 & 173.749 & 185.452 & 6,6 \\
\hline 5 & A5 & 500.000 & $07 / 11 / 2019$ & 27 & S1 & Tani sawit & 10 & 269.257 & 282.715 & 5 \\
\hline 6 & A6 & 100.000 & $26 / 11 / 2019$ & 34 & SMA & $\begin{array}{l}\text { Jual tandan } \\
\text { sawit }\end{array}$ & 5 & 130.016 & 137.166 & 5,5 \\
\hline 7 & A7 & 100.000 & $06 / 12 / 2019$ & 38 & SMA & $\begin{array}{l}\text { Sawit,dagang } \\
\text { lembu, kedai }\end{array}$ & 5 & 93.241 & 98.369 & 5,5 \\
\hline 8 & A8 & 100.000 & $06 / 12 / 20$ & 55 & SMA & Jual-beli botot & 10 & 130.400 & 138.224 & 6 \\
\hline 9 & A9 & 200.000 & $10 / 12 / 2018$ & 47 & SMA & $\begin{array}{l}\text { sawit,buat } \\
\text { kasur }\end{array}$ & 4 & 136.585 & 142.868 & 4,6 \\
\hline 10 & A10 & 250.000 & $24 / 01 / 2020$ & 46 & SMA & $\begin{array}{l}\text { Penggilingan } \\
\text { padi }\end{array}$ & 8 & 183.517 & 195.078 & 6,3 \\
\hline 11 & A11 & 430.000 & $30 / 01 / 2020$ & 43 & SMA & $\begin{array}{l}\text { Tambak } \\
\text { udang,sawah, } \\
\text { kedai,isi ulang } \\
\text { aqua }\end{array}$ & 5 & 298.362 & 315.687 & 5,8 \\
\hline 12 & A12 & 100.000 & $17 / 02 / 2020$ & 39 & SMA & Jual telur bebek & 3 & 73.163 & 76.089 . & 4 \\
\hline 13 & A13 & 200.000 & $14 / 02 / 2020$ & 34 & SMA & Ternak ayam & 5 & 133.840 & 139.931 & 4 \\
\hline 14 & A14 & 200.000 & $26 / 02 / 2020$ & 39 & SMA & Jual kain & 8 & 71.396 & 75.108 & 5,2 \\
\hline 15 & A15 & 300.000 & $28 / 02 / 2020$ & 49 & SMA & Sawit, kedai & 10 & 159.715 & 167.222 & 4,7 \\
\hline 16 & A16 & 100.000 & $13 / 03 / 2020$ & 48 & SMA & $\begin{array}{l}\text { Sawit, bengkel } \\
\text { motor }\end{array}$ & 7 & 70.354 & 73.872 & 5 \\
\hline 17 & A17 & 170.000 & $20 / 03 / 2020$ & 30 & SMA & Panglong & 3 & 70.573 & 74.243 & 6,2 \\
\hline 18 & A18 & 150.000 & $27 / 07 / 2020$ & 41 & SMA & sawit, kedai & 10 & 163.568 & 172.564 & 5,5 \\
\hline
\end{tabular}




\begin{tabular}{|l|l|l|l|l|l|l|l|l|}
\hline & & & & & & & & \\
\hline
\end{tabular}

Sumber : BRI Kantor Cabang Pembantu Tanjung Pura

Keteranagan Tabel :

- Nama nasabah diberi kode A1,A2 ...A18, agar kerahasian nasabah terjaga

- Rata-rata persentase kenaikan laba per tahun (laba bersih setelah bunga dan pajak) seluruh sampel adalah 5, $28 \%$ dibandingkan dengan laba jika hanya memakai modal sendiri. Nasabah yang memperoleh KUR dibawah satu tahun, laba pertahunnya diperoleh dengan mengalikan rata-rata perbulan x 12 .

- Jenis usaha dari nasabah sangat beragam, sehingg sulit untuk dikelompokkan untuk membuat perbandingan antara usaha yang sejenis, kecuali nasabah A3 dadn A8

- Tingkat pendidikan nasabah homogen, rata-rata SMA, sehingga tidak dapat diteliti tentang pengaruh tingkat pendidikan terhadap usaha nasabah satu dengan nasabah lainnya

- Demikian juga masalah usia nasabah (pengalaman/kebijakan) relatif tidak dapat diperbandingkan untuk melihat pengaruhnya terhadap pengelolaan usaha

Dari tabel di atas dapat diolah, dibuat pengelompokan tertentu agar dapat dianalis dengan lebih baik dan terfokus.Untuk keperluan anailis tersebut beberapa tabel dan analisisnya disajikan di bawah ini.

Tabel 2. Perolehan Fasilitas KUR Rp.100 juta s/d Rp.200 juta dan Peningkatan Penghasilan

\begin{tabular}{|l|c|l|l|}
\hline Nomor & Nama & KUR (Rp.) & $\begin{array}{l}\text { Kenaikan } \\
\text { Penghasilan (\%) }\end{array}$ \\
\hline 1 & A1 & $100.000 .000,-$ & 4 \\
\hline 2 & A6 & $100.000 .000,-$ & 5,5 \\
\hline 3 & A7 & $100.000 .000,-$ & 5,5 \\
\hline 4 & A8 & $100.000 .000,-$ & 6 \\
\hline 5 & A12 & $100.000 .000,-$ & 4 \\
\hline 6 & A16 & $100.000 .000,-$ & 5 \\
\hline 7 & A18 & $150.000 .000,-$ & 5,5 \\
\hline 8 & A17 & $170.000 .000,-$ & 5,2 \\
\hline
\end{tabular}




\begin{tabular}{|l|l|l|l|}
\hline 9 & A2 & $200.000 .000,-$ & 4 \\
\hline 10 & A3 & $200.000 .000,-$ & 8 \\
\hline 11 & A9 & $200.000 .000,-$ & 4,6 \\
\hline 12 & A13 & $200.000 .000,-$ & 4 \\
\hline 13 & A14 & $200.000 .000,-$ & 5,2 \\
\hline
\end{tabular}

Ada tiga belas nasabah yang memperoleh KUR dengan nilai Rp.100.000.000,- sampai dengan Rp. 200.000.000,- Persentasi peningkatan penghasilan bervariasi secara tidak teratur dengan range $4 \%-8 \%$. Tidak diperoleh data yang menunjukkan bahwa penerima KUR yang lebih besar nominalnya akan memghasilkan tingkat penghasilan yang lebih tinggi. Nasabah A13 memperoleh KUR Rp.200.000.000,- namun kenaikan tingkat penghasilan (4\%) sama dengan perolehan nasabah A1, A12, dan bahkan lebih rendah dari tingkat perolehan dari A6 (5,5\%), A7 (5,5\%), A8 (6\%).Kenaikan tingkat laba dari nasabah A3 cukup menonjol, sebesar $8 \%$. Nasabah tersebut merupakan pedangan "botot" dana KUR yang diperoleh (sesuai hasil wawancara) dipakai untuk menambah anggota dan armada pencari barang-barang bekas yaitu membuat becak dan memberi modal awal kepada anggotannya sehingga dapat meningkatkan penghasilan lebih tinggi.

Tabel 3. KUR Rp.201 juta s/d Rp. 300 juta

\begin{tabular}{|c|l|l|c|}
\hline No & Nama & $\begin{array}{l}\text { KUR } \\
(\text { Rp. })\end{array}$ & $\begin{array}{l}\text { Peningkatan } \\
\text { Penghasilan } \\
(\%)\end{array}$ \\
\hline 1 & A10 & $250.000 .000,-$ & 6,3 \\
\hline 2 & A15 & $300.000 .000,-$ & 4,7 \\
\hline
\end{tabular}

Hanya dua orang nasabah yang memperoleh KUR antara lebih dari Rp.200 juta sampai dengan Rp.300 juta. Nasabah A10 adalah usaha penggilingan padi, dengan antar jemput, memperoleh peningkatan laba 6,3\%, lebih tinggi dari nasabah A15 (4,7 \%) usaha kebon sawit. Faktor mobilitas mempengaruhi tingkat perolehan ini. Gilingan padi dapat meningkatkan kapasitas mesin untuk beroperasi dengan mengintensifkan penjemputan padi (dengan mobil pick up) ke daerah /desa yang berdekatan. Sedangkan usaha kebon sawit hanya dapat mengintensifkan pemeliharaan sawit dengan menambah pupuk sehingga buah sawit (tandan sawit) dapat dihasilkan maksimal sesuai kriteria yang sudah ada (baku). Untuk menambah atau memperluas 
lahan tidak dapat dilakukan dalam waktu singkat untuk memperoleh hasil, karena proses penanaman dari awal hingga berbuah pasir memakan waktu kurang lebih 5 tahun. Jadi yang dapat dilakukan oleh nasabah pengusaha kebon sawit dengn KUR yang diperoleh adalah menambah stock/persediaan pupuk.

\section{Tabel 4. KUR Rp.400 Juta s/d Rp. 500 Juta}

\begin{tabular}{|l|l|c|l|}
\hline No & Nama & $\begin{array}{c}\text { KUR } \\
(\mathrm{Rp})\end{array}$ & $\begin{array}{c}\text { Peningkatan } \\
\text { Penghasilan } \\
(\%)\end{array}$ \\
\hline 1 & A11 & 430.000 .000 & 5,8 \\
\hline 2 & A4 & 500.000 .000 & 6,6 \\
\hline 3 & A5 & 500.000 .000 & 5 \\
\hline
\end{tabular}

Nasabah A4 adalah petani sawit dan juga jual belilembu.KUR yang diperoleh dapat dipakai utnuk lebih intensif melakukan jual-beli lembu dengan perputaran yang lebih tinggi dari pada sebelum memperoleh KUR, sehingga memperoleh lebih tinggi tingkat penghasilan dibandingkan dengan nasabah A5 yang hanya memiliki usaha kebon sawit. Nasabah A11 mempunyai usaha lebih dari satu dan disokong oleh usaha perdagangan (kedai kelontong dan depot air) sehingga KUR yang diperoleh sebagian dapat dialokasikan kebidang perdagangan selain usaha tambak udang dan tani padi yang relatf tidak dapat "dipaksa" kapasitas maksimumnya.

Tabel 5. Hubungan antara Lama Berusaha danTingkatKenaikan Penghasilan

\begin{tabular}{|c|l|l|c|}
\hline No. & Nama & $\begin{array}{c}1 \text { s/d 5 } \\
\text { Tahun }\end{array}$ & $\begin{array}{c}\text { Kenaikan } \\
\text { Penghasilan } \\
(\%)\end{array}$ \\
\hline 1 & A12 & 3 & 4 \\
\hline 2 & A17 & 3 & 6,2 \\
\hline 3 & A2 & 4 & 4,5 \\
\hline 4 & A9 & 4 & 4,6 \\
\hline 5 & A6 & 5 & 5,5 \\
\hline 6 & A7 & 5 & 5,5 \\
\hline
\end{tabular}




\begin{tabular}{|l|l|l|l|}
\hline 7 & A11 & 5 & 5,8 \\
\hline 8 & A13 & 5 & 6 \\
\hline
\end{tabular}

Tabel 6. LamaLebih Besar dari 5 tahun s/d 10 tahun

\begin{tabular}{|l|l|l|l|}
\hline No. & Nama & $\begin{array}{c}6 \text { s/d 10 } \\
\text { Tahun }\end{array}$ & $\begin{array}{c}\text { Peningkatan } \\
\text { Penghasilan } \\
(\%)\end{array}$ \\
\hline 1 & A1 & 6 & 4 \\
\hline 2 & A16 & 7 & 5,5 \\
\hline 3 & A10 & 8 & 6,3 \\
\hline 4 & A14 & 8 & 5,2 \\
\hline 5 & A5 & 10 & 5 \\
\hline 6 & A8 & 10 & 6 \\
\hline 7 & A15 & 10 & 4,7 \\
\hline
\end{tabular}

Dari dua tabel di atas, lamanya seseorang (nasabah) berusaha tidak mencerminkan akan memperoleh tingkat penghasilan yang lebih tinggi. Justru terlihat ada anomaly dimana nasabah A15 (usaha sawit dan kedai, serta KUR Rp.300 juta) dengan lama berusaha 10 tahun memperoleh tingkat penghasilan 4,7\%, lebih rendah dari nasabah A17 dengan lama berusaha 3 tahun, memperoleh tingkat kenaikan 6,7 \% (usaha panglong, KUR Rp.170 juta).Ada faktorfaktor lain yang mempengaruhi tingkat penghasilan ini.

Tabel 7. Lama Berusaha 11 tahun s/d 15 tahun

\begin{tabular}{|l|c|c|c|}
\hline No. & Nama & $\begin{array}{c}11 \text { s/d 15 } \\
\text { Tahun }\end{array}$ & $\begin{array}{c}\text { Peningkatan } \\
\text { Penghasilan } \\
(\%)\end{array}$ \\
\hline 1 & A3 & 12 & 8 \\
\hline 2 & A4 & 15 & 6,6 \\
\hline
\end{tabular}

Tabel ini juga menunjukkan tidak ada korelasi lamanya usaha seseorang dengan tingkat penghasilan.A3 memperoleh KUR Rp.200 juta, dan A4 Rp.500 juta. Usaha A3 : pedagang botot, dan A4 adalah tani sawit, karet dan ternak lembu.Faktor yang mempengaruhi perbedaan 
itu adalah pedagang botot dapat cepat menjual barang bekas/botot yang dibelinya (turnover peersediaan cepat) sedangkan sawit, karet dan lembu memiliki turn over yang rendah/lama.

Tabel 8. Perbandingan Peningakatan Penghasilan atas Usaha yang Sama

\begin{tabular}{|c|l|l|c|}
\hline No. & Nama & $\begin{array}{c}\text { KUR } \\
\text { Rp. }\end{array}$ & $\begin{array}{c}\text { Peningkatan } \\
\text { Pengahsilan } \\
(\%)\end{array}$ \\
\hline 1 & A8 & 100.000 .000 & 6 \\
\hline 2 & A3 & 200.000 .000 & 8 \\
\hline
\end{tabular}

Nasabah A3 dan nasabah A8sama jenis usahanya yaitu pedagang botot. Kapasitas modal dan usaha A3 (KUR Rp.200 juta) lebih besar dari A8 (KUR Rp.100 juta). Lama berusaha A3 dua belas tahun, A8 sepuluh tahun. Atas usaha yang sejenis dan dengan data-data perbandingan yang ada dapat dianalisis kecenderungan kenaikan tingkat penghasilan masing-masing secara signifikan.

\section{KESIMPULAN DAN SARAN-SARAN}

\section{Kesimpulan}

Dari analisis di atas dapat disimpulkan sebagai berikut :

1. Adanya pemberian fasilitas KUR kepada pengusaha kecil berpengaruh positip terhadap peningkatan penghasilan (laba) pengusaha. Pengaruh positip ini menyangkut berbagai jenis usaha, dari petani, pedagang dengan skala yang berbeda.

2. Dengan pemberian KUR yang berkisar antara Rp.100 juta sampai dengan Rp. 500 juta memberikan peningkatan laba kepada pengusaha kecil dengn rata-rata 5,28 \% Semakin besar KUR yang diterima seorang pengusaha tidak menjamin akan semakin tinggi peningkatan laba yang diperoleh dibandingkan dengan pengusaha yang menerima KUR lebih rendah.

\section{Saran}

1. Pemberian KUR kepada pengusaha kecil masih perlu ditingkatkan dan disosialisasikan lebih gencar sebab belum semua pengusaha kecil memperoleh informasi yang sama atas program KUR tersebut, sehingga masih banyak pengusaha kecil terutama di tingkat pedesaan dan kecamatan belum dapat memanfaatkannya 
2. Perlu penelitian lebih lanjut agar dapat diperoleh data-data dan kesimpulan dengan program KUR ini, jenis usaha apa yang lebih responsif dalam perolehan tingkat kenaikan laba, dengan demikian pihak penyalur KUR dapat lebih intensif mencari nasabah dengan jenis usaha tersebut. Kalau petani/kebon, jenis tanaman apa yang lebih menghasilkan tingkat lebih tinggi. Kalau jenis usahanya perdagangan, bidang perdagangan apa yang dapat memanfaatkan KUR lebih maksimal.

\section{DAFTAR PUSTAKA}

Aritonang,Lerbin Roberto , Metode Penelitian Bisnis,Penerbit Universitas Terbuka, Tangerang Selatan, 2020.

Brotowidjoyo,Mukayat D, Penulisan Karangan Ilmiah, Penerbit Akademika Pressindo, Jakarta, 1985

Cooper, Donald R; C.William Emory ,Meode Penelitian Bisnis, Jilid 1,Penerbit Erlangga, Jakarta 2004.

Keraf,Gorys, Argumentasi dan Narasi, Penerbit PT. Gramedia, Jakarta, 1985

Ngani Nico, Metodologi Penelitian Dan Penulisan Hukum,Penerbit Pustaka Yustisia, Yogyakarta, 2012

Todaro,Michael P, (Penerjemah: Agustinus Subekti), Economics for a Developing World An Introduction to Principles, Problems, and Policies for Development (Ekonomi Untuk Negaranegara Berkembang: Suatu Penagntar tentang Prinsip-prinsip, Maslah dan Kbijakan Pembangunan),1994, Bumi Aksara, Jakarta

Usman,Hussaini; Akbar Purnomo Setiady, Metode Penelitian Sosial, Penerbit Bumi Aksara, Jakarta, 2000

Walean,Sam A, Bank \& Wiraswasta, Wawasan Global, Jakarta, 1990

Undang-undang Dasar 1945 (Amandemen) Republik Indonesia

Undang-undang perbankan No....

Undang-undang Nomor 20 Tahun 2008 tentang Usaha Mikro, Kecil dan Menengah (UMKM)

Instruksi Presiden Republik Indonesia Nomor 6 Tahun 2007 tentang Kebijakan Percepatan Pengemabngan Sektor Riil dan Pemberdayaan Usaha Mikri, Kecil, dan Menengah

Peraturan Menteri Keuangan Republik Indonesia Nomor 22/PMK.05/2010 tentang Perubahan Kedua atas Peraturan Menteri Keuangan Nomor 135/PMK.05/2008 Tentang Fasilitas Penjaminan Kredit Usaha Rakyat

Adam, Latif : Pelibatan Koperasi Dalam Program KUR : Sebuah Inovasi Kebijakan Ekonomi Denag Peluang dan Tantangannya, Jurnal Ekonomi dan Pembangunan Vol.26 No.1, 2018 